University of Nebraska - Lincoln

DigitalCommons@University of Nebraska - Lincoln

Faculty Publications, Department of Psychology

Psychology, Department of

November 2003

\title{
Parenting Characteristics of Women Reporting a History of Childhood Sexual Abuse
}

David DiLillo

University of Nebraska-Lincoln, ddilillo@unl.edu

Amy Damashek

University of Missouri-Columbia, damasheka@gmail.com

Follow this and additional works at: https://digitalcommons.unl.edu/psychfacpub

Part of the Psychiatry and Psychology Commons

DiLillo, David and Damashek, Amy , "Parenting Characteristics of Women Reporting a History of Childhood Sexual Abuse" (2003). Faculty Publications, Department of Psychology. 107.

https://digitalcommons.unl.edu/psychfacpub/107

This Article is brought to you for free and open access by the Psychology, Department of at DigitalCommons@University of Nebraska - Lincoln. It has been accepted for inclusion in Faculty Publications, Department of Psychology by an authorized administrator of DigitalCommons@University of Nebraska - Lincoln. 


\title{
Parenting Characteristics of Women Reporting a History of Childhood Sexual Abuse
}

\author{
David DiLillo \\ University of Nebraska-Lincoln \\ Amy Damashek \\ University of Missouri-Columbia
}

\begin{abstract}
This article reviews research on the parenting characteristics of female survivors of childhood sexual abuse (CSA). Various aspects of parenting are considered, including (a) childbearing patterns, (b) the intergenerational transmission of CSA, (c) maternal reactions to child CSA disclosure, (d) parenting skills and behaviors, (e) parental violence toward children, (f) attitudes toward parenting, and (g) adjustment of survivors' children. Overall patterns suggest CSA survivors may experience difficulties with some aspects of parenting. Among the more consistent trends are findings that survivors may have difficulties establishing clear generational boundaries with their children, may be more permissive as parents, and may be more likely to use harsh physical discipline. Despite associations between CSA and parenting difficulties, the limited research addressing specific aspects of parenting, and limitations in study design, preclude causal inferences and make conclusions tentative at the present time. The clinical implications of this work and directions for future research are discussed.
\end{abstract}

Keywords: sexual abuse, parenting, child maltreatment, child abuse

Research has consistently documented that women with a history of sexual abuse may struggle with a range of mental health problems as adults. These difficulties include posttraumatic stress symptoms, depression, anxiety, and substance abuse (see Polusny \& Follette, 1995, for a review). The long-term correlates of childhood sexual abuse (CSA) may also extend beyond victims themselves to impact survivors' interpersonal relations with significant individuals in their lives. For example, a number of studies suggest that CSA survivors' intimate partner relationships are characterized by lower relationship satisfaction, more overall discord, an increased risk of domestic violence, and a greater likelihood of separation or divorce (Briere, 1984; DiLillo, Giuffre, Tremblay, \& Peterson, 2001; DiLillo \& Long, 1999; Finkelhor, Hotaling, Lewis, \& Smith, 1990; Jehu, 1988).

Relations between adult female survivors and their own children represent another important realm of interpersonal functioning that has recently gained momentum as a topic of systematic research. Understanding the experiences and behaviors of survivors in the parenting role is important not only because it expands our understanding of early sexual abuse in relation to a vital aspect of adult functioning, but also because we may learn about intergenerational implications of survivors' early traumatic experiences for the mental health and well-being of their children. Knowledge about CSA survivors' parenting characteristics and relationships with their children can also illuminate avenues for intervention to help mothers cope with parenting difficulties that may be associated with abusive childhood experiences. Ultimately, such interventions can help to disrupt intergenerational "ripple effects" that may emanate from maternal sexual trauma.

Several theoretical formulations may be applied to help explain an association between CSA and later parenting difficulties. Successful parenting, which is emotionally demanding under any circumstances, may be 
hampered by the maternal psychopathology and distress that have been associated with a history of sexual abuse. The possibility that adult correlates of CSA (e.g., posttraumatic stress symptoms, depression, anxiety, low selfesteem) interfere with parenting is consistent with studies linking maternal mental health problems with diminished parental functioning and poor developmental outcomes for children (Beck, 1998; Petterson \& Albers, 2001; Seifer \& Dickstein, 1993). From a social learning perspective, the high levels of dysfunction found in sexually abusive families (Carson, Gertz, Donaldson, \& Wonderlich, 1990; Harter, Alexander, \& Neimeyer, 1988; Madonna, Van Scoyk, \& Jones, 1991) suggest that victims of intrafamilial sexual abuse may have inadequate opportunities to observe and learn from healthy, effective parenting models. This possibility is supported by reports from mothers with a history of CSA who cite a lack of exposure to models of successful caregiving as an impediment to their own effective parenting (Armsworth \& Stronck, 1999). Attachment theorists have also proposed explanations for linkages between sexual abuse and subsequent parenting problems. For example, Alexander (1992) suggests that the long-term interpersonal correlates of CSA are mediated by the child's attachment style with her primary caregiver. According to this notion, CSA may engender insecure or disorganized attachment among victims, a style carried into adulthood in the form of poor functioning in important interpersonal contexts, including survivors' relationships with their own children. In this manner, insecurely attached mothers are said to "experience anxieties and distortions" in the parenting role (Alexander, 1992, p. 190). Finally, the developmental psychopathology perspective may be important in understanding the variable outcomes associated with a history of CSA. By highlighting the importance of moderating risk and protective factors occurring at various ecological levels and stages of development, this perspective emphasizes the notion that CSA is but one of many experiences with the potential to impact the developmental trajectories of survivors (Cicchetti \& Toth, 2000; Cole \& Putnam, 1992; Trickett \& Putnam, 1993).

The clear theoretical links between CSA and later parenting processes have probably spurred much of the recent research on the parenting practices of adult survivors. However, it should be noted that research in this area is complicated by the substantial co-occurrence of CSA with other risk factors for poor parenting. Prominent among these concomitant risk factors are other forms of maltreatment such as physical or emotional abuse (Claussen \& Crittenden, 1991; Higgins \& McCabe, 2000; Westen, Ludolph, Misle, Ruffins, \& Block,
1990) and parental alcoholism and substance use (McCloskey \& Bailey, 2000). Because concurrent forms of childhood adversity may independently predict adult dysfunction, it is difficult to determine whether CSA is the causal agent responsible for parenting problems reported by survivors. To help sort out the relative impact of co-occurring risk factors, some researchers have treated these secondary variables as covariates during analyses. Although this approach may reveal empirical associations between variables, some authors (Briere, 1988, 1992; Briere \& Elliott, 1993) have noted that the assignment of overlapping variance to covariates can yield rather conservative estimates of the contribution of sexual abuse to later functioning. Recognizing that sexual abuse often occurs hand in hand with other historical risk factors, some researchers have examined the interactive effects of CSA and these variables on later parenting. From a clinical standpoint, this approach can be beneficial because, as children, CSA survivors may frequently have been exposed to a range of family problems with the potential to affect their own parenting.

A second methodological issue concerns the accuracy of abuse reports obtained from participants. As with the broader literature on the long-term correlates of sexual abuse, those studying the CSA-parenting link have relied primarily on retrospective methods, simultaneously asking adult participants to report about childhood sexual abuse experiences and current parental functioning. Of course, in the absence of corroborating data, this technique is problematic because participants may either purposely or unintentionally provide inaccurate accounts of childhood abuse. This imprecision is compounded by variations in the definitions of CSA used across studies. Although there is agreement that certain extreme actions constitute sexual abuse (e.g., father-daughter rape), there is no consensus regarding the appropriateness of labeling other sexual activities as abusive (e.g., sexual intercourse between a 15-year-old girl and her 21-year-old boyfriend). Thus, when considering this literature, it is important to keep in mind that the classification of participants as abused or not abused is inexact and to some degree a subjective process.

Despite these methodological issues, it is important to review the literature on parenting among CSA survivors, for this work currently represents the best source of information on this topic. To identify relevant studies for the present review, published articles examining the association between a maternal history of CSA and parenting were located by using keyword searches in PsycINFO and Medline, as well as by examining published literature reviews on the broader long-term consequences of 
CSA (e.g., Browne \& Finkelhor, 1986; Davis \& PetreticJackson, 2000; DiLillo, 2001; Polusny \& Follette, 1995; Rumstein-McKean \& Hunsley, 2001). The reference sections of individual investigations were also searched for additional studies. These methods revealed a number of empirical articles addressing various aspects of parenting among CSA survivors. For the purposes of this review, findings from these investigations have been organized into seven categories addressing various aspects of the parenting process as experienced by survivors. These include (a) childbearing patterns of CSA survivors, (b) intergenerational transmission of CSA, (c) maternal reactions to child CSA disclosure, (d) parental behaviors, (e) parental violence toward children, (f) attitudes toward parenting, and $(\mathrm{g})$ the ways that a maternal CSA history may impact children's behavioral and emotional adjustment. For each of these topics, relevant research findings will be reviewed.

\section{Childbearing Patterns}

As a group, women with a history of CSA engage in more high-risk sexual behaviors (e.g., more partners and single-occasion sexual encounters, less contraceptive use, involvement in prostitution) than do women with no such history (Fergusson \& Mullen, 1999; Polusny \& Follette, 1995; Widom \& Kuhns, 1996). There is also some indication that female survivors may reach puberty at an earlier age than their nonabused peers (Herman-Giddens, Sandler, \& Friedman, 1988). The possibility of increased sexual activity combined with earlier biological readiness for childbearing raises questions regarding the childbirth patterns of female survivors, specifically whether those who have been sexually abused tend to have more children or give birth at an earlier age than do nonsurvivors.

To date, the data are equivocal regarding this question. There are some indications that sexually abused adolescents and women become pregnant earlier than their nonabused counterparts. For example, Zierler et al. (1991) found that female CSA survivors were 2.6 times more likely than nonabused women to become pregnant before the age of 18. Mothers reporting CSA have also been found to have their first child an average of 1.5 years earlier than do their nonabused peers (Russell, 1986). However, other studies suggest that sexual abuse status may have little independent association with age of first pregnancy beyond that attributable to other demographic factors. In a longitudinal study of 734 North Carolina women, Herman-Giddens et al. (1998) found that CSA status was unrelated to age of first birth once poverty, race, ma- ternal education, marital status, and age had been controlled; however, parity did remain higher for the mothers reporting CSA. Similarly, after taking family and social background into account, Mullen, Martin, Anderson, Romans, and Herbison (1994) reported in their cross-sectional study that only the most severe forms of CSA predicted early pregnancy among survivors.

\section{Intergenerational Transmission of the Risk for CSA}

There is abundant research addressing the inter-generational transmission of childhood physical abuse, with the general consensus being that a childhood history of physical abuse, although not determinative of abusive parenting, is associated with an increased risk of abusing one's own children (Herrenkohl, Herrenkohl, \& Toedter, 1983; Straus, Gelles, \& Steinmetz, 1980; Widom, 2000). Although comparatively little has been done to explore the possibility that the risk for child sexual abuse may be transmitted from one generation to the next, some have speculated about the mechanisms by which such a process might occur. Maker and Buttenheim (2000) hypothesize that identification with the abuser could lead mothers who have been sexually abused to reenact the trauma of their own abuse through sexual victimization of their own children. To date, however, this notion has not been empirically tested. Moreover, unlike physical maltreatment, which may be transmitted through direct perpetration of abuse committed by adult victims against their own children, the relative infrequency with which females perpetrate sexual abuse (Finkelhor, 1979; Russell, 1983) suggests that any intergenerational transmission would most often involve indirect processes in which sexual abuse in the second generation occurs at the hands of someone other than the adult victim herself. This raises the question of whether mothers with a history of sexual abuse may expose their children to high-risk situations, perhaps by allowing contact with male offending partners or other perpetrators outside the home. In speculating about this process, some have suggested that survivor mothers are emotionally distant and removed from their children and that these characteristics may increase their children's vulnerability to sexual victimization by men (Goodwin, McCarthy, \& DiVasto, 1981). Others have suggested that mothers with a history of CSA may involve themselves with men who conform with their past (abusive) models of masculinity or who display sexual interests in children rather than the adult survivor, either of which could increase children's risk of being sexually abused (Faller, 1989). Consistent with these possibilities are reports 
of fear and apprehension on the part of the mothers reporting early sexual abuse regarding their own abilities to protect their children from CSA and other harm (Armsworth \& Stronck, 1999; Herman \& Hirschman, 1981). On the other hand, interviews with incest victims also reveal themes of great concern about children's safety, including difficulty trusting others - even their own husbandswith their children (Cross, 2001; Herman \& Hirschman, 1981; Kreklewetz, \& Piotrowski, 1998).

The sparse empirical data on the intergenerational transmission of sexual abuse risk are also conflicting. Oates, Tebbutt, Swanston, Lynch, and O'Toole (1998) found that Australian mothers of sexually abused children were more likely than were comparison mothers to have been sexually abused as children (34\% vs. $12 \%$, respectively). These authors also explored whether mothers who had experienced CSA were more likely to be involved with male partners who would sexually abuse their children. Findings showed no differences between CSA and non-CSA mothers in the likelihood of their children's experiencing intrafamilial sexual abuse, suggesting that a maternal history of CSA may not predispose mothers to involve themselves with partners who abuse their children (Oates et al., 1998). McCloskey and Bailey (2000) examined maternal history of sexual abuse as one of several factors (marital violence, maternal psychopathology, drug use) previously found to increase children's likelihood of sexual victimization. CSA history was the single strongest predictor of sexual abuse in the next generation, with daughters' risk of abuse being 3.6 times greater when their mothers reported a history of sexual abuse. When occurring in conjunction with maternal drug use, maternal history of CSA further increased daughters' risk for experiencing sexual abuse to an odds ratio of 23.7. In contrast to Oates et al. (1998), the majority of abusers in this study $(60 \%)$ were identified as family members, with $83 \%$ of those being members of the mother's family of origin. Although the authors advise caution in the interpretation of these findings because the proportions reflect small numbers, these results provide some indication that children who have contact with their mothers' perpetrators may have an increased risk of being sexually abused by these individuals as well (McCloskey \& Bailey, 2000). In other words, the same perpetrator may be responsible for the abuse across multiple generations. It is important to note, however, that the participants in the Oates et al. (1998) study were Australian, whereas those in the McCloskey and Bailey (2000) study were low-income Americans, including 35\% Hispanic mothers and 50\% Caucasian mothers. Thus, the differences in these find- ings may be partially due to the cultural backgrounds of the participants.

\section{Maternal Reactions to Children's Disclosure of CSA}

When sexual abuse does occur in consecutive generations, mothers who have been sexually abused may react with greater distress to disclosures of their children's abuse. Briere (1989) suggests that feelings of self-blame, shame, and low self-esteem associated with their own abuse may lead these mothers to react with greater distress to news of their children's maltreatment. Clinical case studies have described mothers with a personal history of sexual abuse re-experiencing the negative emotions of their own victimization upon learning of their child's abuse experience (Green, Coupe, Fernandez, \& Stevens, 1995). Many investigations have examined nonoffending parents' reactions to the abuse of their children and have generally concluded that the disclosure of abuse is quite distressing for mothers (see Elliott \& Carnes, 2001, for a review). However, only three studies have specifically examined whether the presence of a maternal sexual abuse history is a factor in these reactions. Timmons-Mitchell, Chandler-Holtz, and Semple (1996) found that mothers with a history of CSA experienced significantly more symptoms of post-traumatic stress disorder (PTSD) following discovery of their child's abuse than did non-sexually-abused mothers. Similarly, using a Canadian and Aboriginal Canadian sample, Hiebert-Murphy (1998) reported that a history of CSA, in addition to a lack of social support and the use of avoidant coping strategies, was related to greater emotional distress following disclosure of a child's sexual abuse. Deblinger, Stauffer, and Landsberg (1994) reported that mothers' own sexual abuse history was associated with greater feelings of aloneness and personal distress in facing the news of their children's abuse. It is quite possible, however, that differences in distress level may have predated disclosure of the child's victimization, which would weigh against the possibility that the disclosure itself produced increased distress among the mothers with a personal history of CSA (Deblinger et al., 1994).

Interestingly, despite indications that mothers who were sexually victimized may react with increased distress to news of their own children's abuse, Elliott and Carnes's (2001) review noted that several studies have failed to find any direct relationship between maternal abuse history and the degree of support or protection provided to children following the disclosure of abuse (e.g., Deblinger et al., 1994; De Jong, 1988; Heriot, 1996; Hubbard, 1989; Leifer, Kilbane, \& Grossman, 2001). In fact, 
one study found that a maternal history of CSA was associated with increased maternal support of children following abuse disclosure (Morrison \& Clavenna-Valleroy, 1998). In this study, daughters who had been sexually abused viewed mothers with a history of CSA as more supportive than mothers with no such history, both immediately after and 3 months following their own abuse. In fact, at the 3-month follow-up, all mothers with a history of CSA were seen as supportive, whereas only half of the nonabused mothers were viewed similarly.

\section{Parenting Behaviors}

Role reversal. The multifaceted nature of parenting highlights the need to consider that sexual abuse history may influence a variety of subsequent parenting skills and behaviors. One theme emerging from the literature is that of mother-child role reversal, in which mothers who have been sexually abused may become overly dependent on children to meet their own emotional needs. Role reversal, sometimes referred to as "parentification" or boundary dissolution, could result from survivors' difficulty subjugating their own pressing needs to those of their children or perhaps from survivors' having witnessed similar boundary distortions in their families of origin. Role reversal is a concern because, although children subjected to these interactions may initially take on a more mature appearance than their peers, their own development can suffer in the long term (Chase, 1999; Jurkovic, 1997). In an early study, using a modest sample $(N=$ 18) of White, low-income participants, Sroufe, Jacobvitz, Mangelsdorf, DeAngelo, and Ward (1985) observed that mothers reporting a history of incest were more likely to interact with their sons in a subtly seductive manner considered to be indicative of generational boundary dissolution. Burkett (1991) conducted observations of motherchild interactions and found that mothers reporting sexual abuse were more likely to treat their children like a close friend or companion. Interviews from this study also revealed that, compared with nonabused mothers, CSA survivors relied more heavily on their children for emotional support (Burkett, 1991). Similarly, using a middle-class White sample, Alexander, Teti, and Anderson (2000) found a statistical interaction such that mothers who had been sexually abused and who reported unsatisfactory marital relationships also reported more emotional dependence on their own children. Conversely, CSA survivors in satisfying partner relationships showed no signs of role reversal with their children.

Permissive parenting. Several factors suggest that a history of sexual abuse might foster a more permissive approach to parenting. It has been theorized that mothers who experienced sexual abuse may avoid invoking parental authority because of their own negative experiences as victims of adult power (Ruscio, 2001), or that they feel less in control and efficacious in the parenting role and, consequently, lack the confidence necessary to set appropriate limits with children (Cole, Woolger, Power, \& Smith, 1992). In addition, because mothers with a history of CSA may be more emotionally burdened than other mothers due to residual effects from their own abuse, they may simply have less energy to enforce discipline or impart clear behavioral expectations to their children.

Anecdotally, mothers with a history of CSA have reported being easily manipulated by crying children, presumably due to an overidentification with their children's unhappiness (Cross, 2001). Ruscio (2001) employed Baumrind's typology to examine parenting styles among 45 CSA survivors recruited from Massachusetts mental health agencies. Using the Parenting Practices Questionnaire (Robinson, Mandelco, Olsen, \& Hart, 1995), she found that mothers with a history of sexual abuse and those who had an alcoholic parent tended to be more permissive in their parenting behaviors relative to the normative sample for the questionnaire. Lower rates of authoritarian parenting were found only among mothers whose CSA included penetration, whereas no mean differences in authoritative parenting were found between mothers with a history of CSA and the normative sample. In subsequent analyses controlling for physical abuse history, parental alcoholism, and current socioeconomic status, maternal CSA history retained its negative association with authoritarian parenting. However, this relationship was moderated by dysfunctional parenting attitudes such that mothers whose abuse involved penetration reported more dysfunctional parenting attitudes, whereas other survivors did not. This study found no independent association between CSA and permissive parenting beyond that attributable to the covariates. In another study addressing parental permissiveness, incest survivors were found to place fewer maturity demands on their children than did mothers with an alcoholic parent or comparison mothers (Cole et al., 1992). Using a different but similarly Caucasian and middle-class sample, the same authors compared incestuously to non-incestuously abused mothers and found that incest survivors were more indulgent with their children and allowed children more behavioral license than did nonincestuously-abused mothers, especially those women who perceived their own mothers as negatively controlling or uninvolved (Cole \& Woolger, 1989). 
Parenting skills and abilities. A closely related issue to that of parental permissiveness is the question of whether mothers with a history of CSA may be less skilled in parenting than are non-CSA mothers. Diminished parenting abilities may be due to several factors, including a lack of positive parenting role models or depleted emotional resources needed for successful caregiving. Cole et al. (1992) found that incest survivors saw themselves as less skilled (i.e., less controlled, organized, and consistent) as parents than did a group of comparison mothers. T. Cohen (1995) found that a history of CSA was associated with poorer parenting as assessed by the Parenting Skills Inventory (Nash \& Morrison, 1984). In this study, mothers who had been sexually abused reported poorer parental functioning across several Parenting Skills Inventory subscales, including role support, role image, objectivity, expectations, rapport, communication, and limit setting. Although these findings suggest that incest survivors may have deficits in parenting skills, the association may be overestimated in this study due to the fact that sexually abused participants were recruited from a treatment clinic, whereas control group mothers were recruited from the community.

Addressing issues of sexuality with children. Maternal CSA survivors have been found to discuss the details of male and female sexual development and topics related to contraception in more detail with their children than do nonabused mothers (Grocke, Smith, \& Graham, 1995). This tendency toward increased communication about sexuality can be seen as beneficial, perhaps resulting from survivors' being more attuned to the threat of sexual abuse and feeling that education and open communication about sexuality will protect their children against such experiences. However, in a somewhat contradictory finding, Douglas (2000) reported that Scottish mothers with a history of CSA-particularly those who reported that their fathers were less caring-were much more anxious about engaging in parenting behaviors that involved being physically intimate with their children. These behaviors included changing diapers, bathing children, and tucking them into bed. Although these activities are not explicitly sexual in nature, apprehension about performing intimate activities with young children may be suggestive of later discomfort in addressing overtly sexual issues with more mature children. One possible reason for the somewhat contradictory findings between these two studies is that Grocke et al. (1995) used a community sample, whereas Douglas's (2000) sample consisted of participants currently in mental health treatment. In addition, these studies were completed in different countries, and thus it is difficult to know how cultural norms related to sexuality may play a role in these findings.

\section{Physically Abusive Parenting}

As noted, there is general agreement that a history of child maltreatment in the form of childhood physical abuse represents a risk factor for physically abusing one's own children (Gelles \& Straus, 1987; Pianta, Egeland, \& Erickson, 1989; Whipple \& Webster-Stratton, 1991). Lack of parenting skills as well as poor emotional regulation are characteristics known to place physically abused parents at risk for using harsh physical punishment with their children (Azar \& Twentyman, 1986; Egeland, Breitenbucher, \& Rosenberg, 1981). Studies reviewed here, which suggest the possibility of similarly diminished parenting skills among CSA survivors, in addition to findings linking sexual abuse with longterm anger and stress management difficulties (Briere \& Runtz, 1988; Courtois, 1988; Donaldson \& Gardner, 1985; Newman \& Peterson, 1996; Scott \& Day, 1996), indicate that women who experienced early sexual abuse may also be at risk of resorting to physically harsh parenting with their own children. Despite this possible connection, CSA has only recently received attention as a potential precursor to abusive parenting.

In a prospective study addressing this issue, Spieker, Bensley, McMahon, Fung, and Ossiander (1996) examined whether adolescent mothers who had been sexually abused were more likely than others to sexually abuse, physically abuse, or neglect their own children. With histories of childhood physical abuse among parents statistically controlled, these investigators found that sexual abuse as a child independently predicted adult investigation by Child Protective Services (CPS). Mothers who reported a history of chronic sexual abuse were significantly more likely than non-sexually-abused women to have had CPS contact (adjusted odds ratio $=25.1$ ). Even mothers whose own abuse had been brief in duration or consisted of a single incident were 2.6 times as likely to have had contact with CPS. The percentages of study participants reporting contact with CPS were 15.4, 38.5, and 83.3 for mothers who had experienced no CSA, brief CSA, and chronic CSA, respectively. This pattern of findings is consistent with those of Boyer and Fine (1992), who reported a higher rate of CPS contact for mothers who had been sexually abused (21\%) compared with those who had not (8\%), although it was unclear to what extent survivors themselves were the alleged perpetrators. Using a predominantly low-income, African- 
American sample of children who were medically and psychosocially at risk, Dubowitz et al. (2001) found that mothers with a history of both physical and sexual abuse used physically harsher parenting practices than did those who had experienced either sexual abuse or physical abuse or had no abuse history at all. This suggests a possible cumulative impact of multiple forms of childhood maltreatment on later child abuse potential. Among a similar sample of predominantly (79\%) African-American low-income mothers, Banyard (1997) found that maternal CSA history predicted the use of physical violence and harsh parenting as a tactic for dealing with parentchild conflicts, an association that remained when the effects of physical abuse and other negative family-of-origin experiences were partialled out.

Hall, Sachs, and Rayens (1998) studied the roles of CSA history and social resources (again among low-income, African-American women) in predicting child abuse potential, as assessed by the Child Abuse Potential Inventory (Milner, 1986). These authors found that although sexual and physical abuse in childhood were each related to an increased risk of abusing one's own child, sexual abuse was the stronger of the two predictors, especially in combination with low social resources. In this study, a greater severity of sexual abuse was found to predict increased abuse potential scores. This result is similar to that of Zuravin, McMillen, DePanfilis, and RisleyCurtiss (1996), who found that a maternal history of sexual abuse involving intercourse (as opposed to less invasive CSA) was related to increased chances of physical abuse, sexual abuse, or neglect in the second generation. In contrast to Hall et al. (1998), however, these authors found that no single type of maltreatment history was more potent than others in predicting second generation maltreatment. This difference in findings may be due to the fact that Hall et al. (1998) assessed a specific type of abuse outcome - potential for physically harsh parenting - whereas Zuravin et al. (1996) used an aggregated maltreatment score that combined physical abuse, sexual abuse, and neglect. Finally, DiLillo, Tremblay and Peterson (2000) explored the link between maternal CSA history and later child abuse potential as well but also examined the role of maternal anger in mediating this association. Again, with maternal history of physical abuse as a covariate, maternal CSA history predicted increased potential for physical abuse of one's children. Additionally, maternal anger mediated the CSA-abuse potential link, thus shedding light on one pathway through which CSA may increase child abuse potential (DiLillo et al., 2000).

Despite several studies suggesting an association between CSA and later harsh parenting, this relationship may not be entirely robust. For example, Zuravin and Fontanella (1999) found a significant bivariate relationship between CSA and severe violence toward children, but this association became nonsignificant after accounting for other negative childhood experiences such as physical abuse and neglect. However, the authors of this study note that low internal reliability of their parental violence measure (an adapted version of Straus's Conflict Tactics Scale) necessitated dichotomizing these scores into two levels, a procedure that may have resulted in a less sensitive measure of these events.

\section{Parenting Attitudes}

Perceptions of parenting. If, as some research suggests, CSA is predictive of impaired parenting abilities in several areas, a related question is whether such behaviors may reflect similarly atypical attitudes and perceptions about parenting. One theme relevant to this issue concerns survivors' perceptions of their own parenting experiences and abilities. Qualitative reports reveal a general concern on the part of mothers with a history of CSA that they may be bad parents (Herman \& Hirschman, 1981). There is also some indication that a history of CSA may be associated with "black and white" perceptions of oneself as a parent. For example, Burkett (1991) found that during a semistructured interview, nonabused mothers tended to report both the benefits and drawbacks of parenting, whereas mothers with a history of CSA revealed a less balanced perception of parenting, reporting primarily either the rewards or the drawbacks. In addition, some reports suggest that a history of incest may diminish mothers' feelings of confidence in their own parenting (Cole et al., 1992). Finally, Banyard (1997) noted that a history of CSA was negatively related to satisfaction with oneself as a parent, over and above the effects of other adverse childhood experiences (e.g., physical abuse, negative relationships with caregivers) and maternal depression.

Parental anxiety and stress. A second theme is that of anxiety and apprehension about parenting duties. Banyard (1997) found that a history of CSA had no independent association with maternal expectations about parenting or frequency of worry about child behavior problems, once other negative childhood experiences as well as demographic and mental health variables had been covaried. Similarly, Alexander et al. (2000) found no association between maternal CSA history and scores on the Parenting Stress Inventory (Abidin, 1995). However, as noted previously, Douglas (2000) reported anxiety and 
distress among survivor mothers in relation to the "intimate" aspects of parenting young children. Specifically, a longer duration of CSA may be associated with greater distress about the intimate aspects of parenting. Nevertheless, because the study did not control for demographic or other background variables, it is difficult to evaluate the unique relationship between sexual abuse and anxiety about parenting.

\section{Children of CSA Survivors}

When examining CSA survivors' roles as mothers, it is important to consider not only parenting behaviors and attitudes, but also the ways in which these actions may affect children on a behavioral, emotional, and social level. After all, it is through these processes that the consequences of sexual abuse may reverberate from one generation to the next. Because of the major socializing role that mothers play for children (Bowlby, 1977; Daro, 1988) and the possibility that a personal history of sexual abuse may influence a range of parenting behaviors, it is crucial to examine whether the children of mothers who have been sexually abused face unique challenges or perhaps experience negative developmental outcomes related to their mothers' history of sexual trauma.

Several sources suggest a link between maternal CSA status and child functioning. Lyons-Ruth and Block (1996) conducted a longitudinal study to examine the attachment styles of infants of low-income mothers who had experienced abuse, neglect, or other violence. These researchers gathered observational and interview data at three points-when children were approximately 18 months, 8 years, and 9 years old - and found that levels of infant distress were significantly related to the severity of mothers' childhood trauma experiences. More specifically, infant distress increased linearly with mothers' exposure to childhood trauma, such as physical or sexual abuse. Among infants who displayed an insecure attachment style, those whose mothers had been exposed to childhood trauma were significantly more likely to display a disorganized attachment style than the other insecurely attached infants. Maternal CSA history also had the strongest relationship to decreased maternal involvement with infants and restricted maternal affect; this relationship strengthened as severity of abuse increased. Burkett's (1991) observations of mother-child interactions revealed that children of mothers who had been sexually abused may be more parent-focused (rather than selffocused) compared with control children. In particular, these children showed more helping, protective, manag- ing, and controlling behaviors toward family members, whereas the children of nonabused mothers showed significantly more trusting, relying, deferring, and submitting behaviors (Burkett, 1991). Although some of the behaviors observed in the children of CSA survivors can take on positive meaning in certain contexts, Burkett viewed these findings as reflective of a role reversal pattern in these relationships. In contrast to these data, Oates et al. (1998) found no differences between older children of mothers who had and had not experienced sexual abuse in their perceptions of their mothers' care and protection in the personal or social sphere. Finally, some research suggests that children of mothers with a history of CSA may be more wary about danger in their environments. For instance, Grocke et al. (1995) found that children of CSA survivors were more likely than those of nonabused mothers to interpret ambiguous pictures of children and strangers as being negative or threatening.

With regard to general psychopathology and behavioral problems, several studies have found that children whose mothers experienced CSA exhibit greater internalizing and externalizing symptomatology than do other children. Researchers have noted that the children of CSA survivors score higher on the Child Behavior Checklist (CBCL), as reported by both mothers (Dubowitz et al., 2001) and fathers (Buist \& Janson, 2001). However, Buist and Janson (2001) found differences between mothers' and fathers' perceptions, such that fathers rated their children higher on the CBCL than did fathers of control children, whereas mothers did not. Paredes, Leifer, and Kilbane (2001) found positive correlations between mothers' trauma scores and sexually abused children's internalizing scale scores as well as problems in the mothers' family of origin and children's externalizing scale scores. They also found increased total CBCL scores for sexually abused children whose mothers had a history of CSA, in comparison with those whose mothers had no such history.

Despite these indications that maternal CSA status may be related to child behavior problems, three studies have not confirmed such links. Alexander et al. (2000) found no main or interactive effects of maternal CSA history or marital satisfaction on child behavior problems as assessed with the CBCL. By and large, Oates et al. (1998) found that sexually abused children whose mothers had experienced CSA were no more likely to display low self-esteem, depression, or behavioral problems than were children of nonabused mothers, at the time of initial assessment or at 18 month and 5-year follow-ups (a minor exception was that survivors' children reported lower self-esteem at initial assessment). A rather striking find- 
ing by Timmons-Mitchell, Chandler-Holtz, and Semple (1997) was that sexually victimized children of CSA survivors (mean age 8.3 years) were less likely than were the children of nonabused women to experience PTSD symptoms stemming from their own abuse. The reason for this finding is unclear, but it is possible that CSA survivors may draw on their own abuse experiences to help children cope with their victimization. Alternatively, CSA survivors in that study may have underreported children's PTSD symptoms, perhaps as part of an avoidant coping process.

In perhaps the only study of adult offspring, Voth and Tutty (1999) conducted unstructured interviews with six Canadian-born Caucasian daughters of incest survivors and reported that these grown children perceived their mothers to be emotionally immature, angry, needy, and passive and that they did not act to protect their daughters or enforce household rules. These daughters observed that their mothers sometimes exploded with anger, causing them to feel guilty and, ultimately, like "bad" children. With regard to parenting, the adult daughters reported lacking "blueprints" for how to parent well and that they found themselves repeating some of their own negative childhood experiences with their own children ( $\mathrm{p}$. 37). Although based on only six participants and lacking a comparison group, this study may provide initial insight into possible long-term repercussions for children of mothers who were sexually abused.

\section{Summary}

In summarizing the findings reviewed here, it is important to bear in mind that this area of research is in the early stages of development, which means that relatively few studies have addressed any single aspect of parental functioning among CSA survivors. Although the nascent state of the literature makes it difficult to draw firm conclusions at the present time, a convergence of data from different sources provides at least suggestive evidence that a maternal history of sexual abuse may be associated with difficulties with certain aspects of parenting. For example, data from three studies (Alexander et al., 2000; Burkett, 1991; Sroufe et al., 1985) — two of which utilized direct behavioral observation - suggest that mothers who have been sexually abused may have greater difficulty establishing appropriate hierarchical boundaries with children. Likewise, multiple investigations have found that CSA survivors may be overly permissive (Cole \& Woolger, 1989; Cole et al., 1992; Ruscio, 2001), or, alternatively, may use excessively harsh discipline techniques with their children (DiLillo et al., 2000; Dubowitz et al., 2001; Hall et al., 1998; Spieker et al., 1996; Zuravin et al., 1996). Together, these findings suggest that mothers with a history of CSA may be slow to set limits with their children, but when they do, they may resort to rather harsh or punitive methods. Regarding the possibility that the risk of sexual abuse may be transmitted across generations, two retrospective studies have found that the children of CSA survivors experience an increased likelihood of being sexually abused than do children of nonabused mothers (McCloskey \& Bailey, 2000; Oates et al., 1998), although it remains unclear whether abuse in the second generation is more likely to be committed by an intrafamilial or an extrafamilial offender. Studies also suggest that women with a history of CSA may react with greater distress upon learning that one of their children has experienced sexual abuse (Deblinger et al., 1994; HiebertMurphy, 1998; Timmons-Mitchell et al., 1996). At the same time, however, most investigations have not found a relationship between maternal abuse history and the level of support or protection provided to children in the aftermath of their abuse (Deblinger et al., 1994; De Jong, 1988; Heriot, 1996; Hubbard, 1989; Leifer, Kilbane, \& Grossman, 2001), with the exception of one investigation reporting that mothers with a history of CSA were more supportive of their victimized children than other mothers (Morrison \& Clavenna-Valleroy, 1998).

Data regarding the functioning of survivors in several other areas of parenting are more limited and sometimes inconsistent across studies, which leaves the association between maternal CSA and these domains more difficult to discern. For example, current findings do not clearly answer the question of whether a history of CSA is related to altered childbearing patterns. This connection may exist only in circumstances of severe abuse, or may be completely attributable to concomitant third variables. The findings regarding parenting-related stress and perceptions of oneself as a parent are similarly inconsistent. Some investigations report that survivors have atypical concerns about their own effectiveness and competence as parents (Banyard, 1997; Cole et al., 1992; Douglas, 2000; Herman \& Hirschman, 1981). On the other hand, others indicate that mothers with a history of CSA may be no more stressed about parental performance than are nonabused mothers (Alexander et al., 2000; Banyard, 1997). Results are also varied regarding the behavioral and emotional adjustment of CSA survivors' children, with some researchers reporting increased child problems on checklists such as the CBCL (Buist \& Janson, 2001; Burkett, 1991; Dubowitz et al., 2001; Paredes et al., 2001), and others finding no discernable problems associated with 
a maternal history of CSA (Oates et al., 1998; TimmonsMitchell et al., 1997). Finally, to date, only a single study has directly compared the parenting abilities of mothers with and without a history of CSA (T. Cohen, 1995). Although results were indicative of skill deficits among CSA survivors, the complex nature of parenting and the methodological limitations of that study suggest that it is premature to make generalized statements about the parenting skills of CSA survivors.

It is worth noting again that, as children, CSA survivors are likely to have also experienced other risk factors for poor parenting, the presence of which interferes with efforts to identify the unique relationship between early sexual abuse and parental adjustment. As noted, some investigators have addressed this issue either by statistically isolating variance associated with CSA or by examining the combined or interactive impact of CSA and other variables on subsequent parenting. In general, results from both strategies point to CSA as an important etiological factor in the development of later parenting difficulties. In some cases, a history of sexual abuse has been found to maintain a significant - though sometimes weaker- association with parenting outcomes, even when concomitant risk factors have been statistically controlled (e.g., Banyard, 1997; DiLillo et al., 2000). In addition, studies examining the interactive impact of exposure to sexual abuse and other childhood adversities (e.g., parental alcoholism, physical abuse) suggest that this nexus of risk factors may be especially detrimental to later parental adjustment (e.g., Alexander et al., 2000; Dubowitz et al., 2001; McCloskey \& Bailey, 2000).

It should also be emphasized that there are methodological factors that preclude causal conclusions about the CSA-parenting link at this time. Chief among these issues is the correlational nature of this work and the fact that most studies have relied on retrospective reports of maternal CSA. Until prospective investigations with verified abuse victims can be conducted, CSA is best characterized as a risk factor that may operate in the context of other developmental adversities (e.g., parental alcoholism, other forms of abuse) to increase the likelihood of impairment in some aspects of parenting. Furthermore, as already noted, the relatively few studies that focus on any one facet of parenting suggest that even the positive findings reviewed here should be considered with caution until such time that replication with additional samples can occur. Finally, because the published literature tends to emphasize statistically significant findings (and filter out others), it is possible that focusing only on published reports may overstate the CSA-parenting link. Future metaanalytic studies could take into account this "file-drawer effect" and may also be useful in objectively quantifying the CSA-parenting association, once a sufficient number of studies becomes available.

\section{Future Research Needs}

Although more investigations are needed across many realms of parental functioning among survivors, certain aspects of this relationship are especially deserving of additional research attention. One such area concerns CSA as a predictor of physically abusive parenting. Initial data give cause for concern because this research highlights CSA as a potentially potent risk factor for the physical abuse of one's own children (an association that may exist independently of parental history of physical abuse). However, because of the retrospective nature of present findings, much more work will be needed to clarify this relationship. Longitudinal studies that address possible interactions between exposure to multiple childhood adversities (sexual abuse, physical abuse, neglect, parental alcoholism) and later harsh parenting would be especially useful.

The related question of whether a maternal history of CSA increases the risk of survivors' children being sexually abused is also in need of clarification. Additional work is required to explore this association further and, should a link be confirmed, to determine the mechanisms by which the risk of sexual abuse is transmitted from one generation to the next. Studies of adult survivors' tendencies to adopt a protective stance toward their children, particularly regarding their abilities to defend children against sexual advances from their own perpetrators or other predatory males, will be an important starting point for this research. Difficulties protecting children could be related to a number of factors, including poor threat recognition on the part of some survivors, especially those who have been multiply victimized (see Wilson, Calhoun, \& Bernat, 1999); a pervasive lack of self-efficacy (i.e., learned helplessness); profound depression (and resultant inactivity); or a general preoccupation with one's own prodigious needs. In pursuing this topic, investigators should consider nonmaternal risk factors as well and should be mindful not to place unintended blame on adult victims. Possible mediating or moderating factors outside the survivor herself include family structure (e.g., the presence or absence of siblings or a stepfather) and neighborhood conditions (e.g., dangerousness, nature and degree of contact with neighbors), either of which could affect the risk of sexual abuse.

Knowledge about the psychosocial functioning of survivors' children is important because maladjustment in 
this group would suggest an indirect or systemic impact of CSA. As noted, some data indicate that survivors' children display more internalizing and externalizing behaviors as assessed by informant checklists, whereas other studies find no evidence of behavioral or emotional problems. Additional research to clarify these discrepancies, as well as to more thoroughly explore the attachment and boundary-related issues in survivor/mother-child dyads, will be helpful. In addition, although very little is known about the adjustment of adult children of survivors, anecdotal reports suggest that these individuals view their mothers negatively (as angry, needy, immature), and may themselves struggle with interpersonal difficulties (Voth \& Tutty, 1999). Additional work will be needed to explore these issues and to pinpoint the specific behaviors and interactional patterns that may result in problems experienced by survivors' adult offspring.

Finally, there are some important areas that have yet to receive attention in the literature. First, several findings reviewed here suggest that many CSA survivors fare no worse than nonabused women in certain aspects of parenting. These results indicate that a substantial proportion of survivors are resilient to the harmful outcomes associated with sexual abuse. Future research that focuses specifically on survivors who become effective parents can be useful in developing interventions that bolster parenting strengths and resilience among those with a history of CSA. Second, too few studies have differentiated among different types of sexual abuse, such as those involving incest versus extrafamilial acts. It might be hypothesized that these experiences would have differential long-term correlates within the realm of parenting. Lastly, there currently appear to be no investigations of parenting among male CSA survivors. This is a significant void in the literature, considering the increasingly integral role that fathers often play in child rearing.

\section{Clinical Implications}

Parenting issues among CSA survivors can come to the attention of clinicians in a variety of ways. Those working primarily with adults should be cognizant of the possibility that effective parenting may be particularly difficult for those with a history of CSA. Helping adult survivors modulate their affective and behavioral responses may be useful in avoiding an all-or-nothing (i.e., too lenient or overly harsh) style of reacting to child misbehavior. Cross (2001) has noted that the Parenting Stress Index (Abidin, 1995) may be a useful measure for assessing these difficulties. Because CSA may be a risk factor for physically harsh parenting, more specific measures, such as the Child Abuse Potential Inventory (Milner, 1986) or the Parental Anger Inventory (Sedlar \& Hansen, 2001) can also shed light on whether parental frustration will spill over into abusive behaviors. A related therapeutic concern stems from the possibility that survivors' children may have an increased risk for sexual abuse committed by male perpetrators, such as a live-in partner. Although the actual extent of this risk and potential mechanisms remain unclear, it is well known that survivors of CSA themselves experience high rates of revictimization, which may in part be associated with problems of risk recognition (Wilson et al., 1999). If risk recognition difficulties become generalized, these tendencies could place survivors' children at an increased risk of victimization. It may therefore be beneficial to assess supervision levels and other actions that survivors take to protect their children from threats of interpersonal harm.

A related issue concerns CSA survivors' understanding of typical child development. Because of their own abusive histories and related family dysfunction, some survivors may lack an adequate understanding of normative sexual development in particular. Anecdotally, we have observed that mothers with a history of CSA may misinterpret innocuous behaviors of very young children (e.g., reprimanding a 4-year-old for dancing "sexy") while appearing indifferent about more risky actions of older children (e.g., a 13-year-old daughter "dating" a 20-year-old male). Thus, as noted by Cross (2001), CSA survivors may benefit from interventions that include efforts to assist them in acquiring a more accurate understanding of developmental norms, especially related to sexuality.

Group therapy is another treatment modality that could be utilized for mothers with a history of CSA. Cross (2001) reported that female survivors in a parenting focus group found the experience to be therapeutic. More formalized group treatment protocols could be developed to help adult survivors share and cope with their unique parenting struggles. These treatments could consist not only of general topics relevant to effective, nonabusive parenting, such as stress and time management, the importance of consistency, and proper use of time-out (a task notoriously difficult for parents with poor affect regulation), but also could provide a forum for survivors to gain insight from each other about the ways in which their own abuse histories and other family-of-origin issues may be related to current parenting issues.

Clinicians working with children, particularly youths who are at risk for or have experienced maltreatment, may also encounter issues related to a mother's history of CSA. In fact, in light of work reviewed here suggest- 
ing parent-child difficulties related to maternal CSA history (e.g., Burkett, 1991; Cole et al., 1992; Lyons-Ruth \& Block, 1996), survivors' children might be especially likely to receive referrals for mental health services. Although some studies indicate that these children may display behavioral and emotional difficulties, there is no telltale symptom pattern indicative of problems associated with maternal CSA history. Clinicians should nevertheless be aware that certain difficulties may be more specifically linked to parental history of CSA. Mother-child role reversal, for example, is one problem that might prompt clinicians to explore the possibility that maternal CSA history is an issue. Children who interact with mothers in an unexpectedly mature manner but who have difficulties in other areas, such as school and peer relations, may be experiencing role reversal prompted in part by a maternal history of CSA. In such cases, interactional patterns indicative of boundary distortions can be assessed through observation of parent-child play or perhaps through simple questions like those used by Alexander et al. (2000).

Clinicians working with sexually abused children and their nonoffending mothers should also consider the implications that a maternal history of CSA may have for the therapeutic process. Findings reviewed here suggest that many mothers with a personal history of CSA can provide much needed support to children following abuse. Presumably, a mother's own history of CSA may make it easier to believe a child's claims of abuse and can strengthen the survivor's resolve to protect that child from further victimization. At the same time, it is conceivable that news of a child's victimization may trigger maternal distress related to her own abuse, which could interfere with providing adequate support and protection to a child. Practitioners working with sexually abused children should consider inquiring about maternal history of CSA, particularly if personal distress appears to hinder a nonoffending mother from participating fully in the support and treatment of her child. This is especially important, considering the crucial role that maternal support plays in child adjustment following sexual abuse (Conte \& Schuerman, 1987; Johnson \& Kenkel, 1991; Mannarino \& Cohen, 1996). Several authors have written extensively about the involvement of nonoffending parents in empirically supported interventions for children who have experienced sexual abuse (e.g., Celano, Hazzard, Webb, \& McCall; 1996; J. A. Cohen \& Mannarino, 1993; J. A. Cohen \& Mannarino, 1996; J. A. Cohen \& Mannarino, 1997; J. A. Cohen \& Mannarino, 1998; Deblinger \& Heflin, 1996; Deblinger, Lippmann, \& Steer, 1996; Deblinger, McLeer, \& Henry, 1990; Deblinger, Steer, \& Lippmann, 1999; Hansen, Warner-Rogers, \& Hecht, 1998; Stauffer \& Deblinger, 1996).

\section{CONCLUSIONS}

It is well known that a significant proportion of the female population experiences some form of sexual victimization during childhood or adolescence. Studies are beginning to document that the negative correlates of this abuse are by no means limited to difficulties residing within individual survivors. Rather, the possible sequelae of sexual abuse may also encompass survivors' abilities to maintain stable and effective interpersonal relationships as adults. In focusing on one major aspect of interpersonal functioning - parenting relations - this review highlighted several aspects of these interactions that appear to be associated with early sexual abuse experiences. Although CSA can currently be seen as a risk factor for certain parenting difficulties, further research is needed to clarify the associations between child sexual abuse and subsequent parenting. Such research can aid in the development of treatments to help female survivors deal with the unique challenges they may face as parents, as well as to curb the potential for CSA to have an indirect impact across multiple generations.

\section{REFERENCES}

Abidin, R. R. (1995). Parenting Stress Index (3rd ed.). Odessa, FL: Psychological Assessment Resources.

Alexander, P. C. (1992). Application of attachment theory to the study of sexual abuse. Journal of Consulting and Clinical Psychology, 60, 185-195.

Alexander, P. C., Teti, L., \& Anderson, C. L. (2000). Childhood sexual abuse history and role reversal in parenting. Child Abuse \& Neglect, 24, 829-838.

Armsworth, M. W., \& Stronck, K. (1999). Intergenerational effects of incest on parenting: Skills, abilities, and attitudes. Journal of Counseling \& Development, 77, 303-317.

Azar, S. T., \& Twentyman, C. T. (1986). Cognitive behavioral perspectives on the assessment and treatment of child abuse. In P.

C. Kendall (Ed.), Advances in cognitive behavioral research and therapy (Vol. 5, pp. 237-267). New York: Academic Press.

Banyard, V. L. (1997). The impact of childhood sexual abuse and family functioning on four dimensions of women's later parenting. Child Abuse \& Neglect, 21(11), 1095-1107.

Beck, C. T. (1998). The effects of postpartum depression on child development: A meta-analysis. Archives of Psychiatric Nursing, 1, 12-20.

Bowlby, J. (1977). The making and breaking of affectional bonds. British Journal of Psychiatry, 130, 201-210.

Boyer, D., \& Fine, D. (1992). Sexual abuse as a factor in adolescent pregnancy and child maltreatment. Family Planning Perspectives, 24, 4-11.

Briere, J. (1984, November). The effects of childhood sexual abuse on later psychological functioning: Defining a "post-sexualabuse" syndrome. Paper presented at the Third National Conference on Sexual Victimization of Children, Washington, D.C. 
Briere, J. (1988). Controlling for family variables in abuse effects research: A critique of the "partialling" approach. Journal of Interpersonal Violence, 3, 80-89.

Briere, J. (1989). Therapy for adults molested as children. New York: Springer.

Briere, J. (1992). Methodological issues in the study of sexual abuse effects. Journal of Consulting and Clinical Psychology, 60, 196-203.

Briere, J., \& Elliott, D. M. (1993). Sexual abuse, family environment, and psychological symptoms: On the validity of statistical control. Journal of Consulting and Clinical Psychology, 61, 284-288.

Briere, J., \& Runtz, M. (1988). Post sexual abuse trauma. In G. E. Wyatt \& G. J. Powell (Eds.). Lasting effects of child sexual abuse (pp. 85-99). Newbury Park, CA: Sage.

Browne, A., \& Finkelhor, D. (1986). Impact of child sexual abuse: A review of the research. Psychological Bulletin, 99, 66-77.

Buist, A., \& Janson, H. (2001). Childhood sexual abuse, parenting and postpartum depression-a 3-year follow-up study. Child Abuse \& Neglect, 25, 909-921.

Burkett, L. P. (1991). Parenting behaviors of women who were sexually abused as children in their families of origin. Family Process, 30, 421-434.

Carson, D. K., Gertz, L. M., Donaldson, M. A., \& Wonderlich, S. A. (1990). Family-of-origin characteristics and current family relationships of female adult incest victims. Journal of Family Violence, 5, 153-171.

Celano, M., Hazzard, A., Webb, C., \& McCall, C. (1996). Treatment of traumagenic beliefs among sexually abused girls and their mothers: An evaluation study. Journal of Abnormal Child Psychology, 24, 1-17.

Chase, N. D. (Ed.). (1999). Burdened children: Theory, research, and treatment of parentification. Thousand Oaks, CA: Sage.

Cicchetti, D., \& Toth, S. L. (2000). Developmental processes in maltreated children. In D. J. Hansen (Ed.), Motivation and child maltreatment (Vol. 46, pp. 85-160). Lincoln: University of Nebraska Press.

Claussen, A. H., \& Crittenden, P. M. (1991). Physical and psychological maltreatment: Relations among types of maltreatment. Child Abuse and Neglect, 15, 5-18.

Cohen, J. A., \& Mannarino, A. P. (1993). A treatment model for sexually abused preschoolers. Journal of Interpersonal Violence, 8, 115-131.

Cohen, J. A., \& Mannarino, A. P. (1996). A treatment outcome study for sexually abused preschool children: Initial findings. Journal of the American Academy of Child and Adolescent Psychiatry, $35,42-50$.

Cohen, J. A., \& Mannarino, A. P. (1997). A treatment study for sexually abused preschool children: Outcome during a oneyear follow-up. Journal of the American Academy of Child and Adolescent Psychiatry, 36, 1228-1235.

Cohen, J. A., \& Mannarino, A. P. (1998). Interventions for sexually abused children: Initial treatment outcome findings. Child Maltreatment, 3, 17-26.

Cohen, T. (1995). Motherhood among incest survivors. Child Abuse \& Neglect, 19(12), 1423-1429.

Cole, P. M., \& Putnam, F. W. (1992). Effect of incest on self and social functioning: A developmental psychopathology perspective. Journal of Consulting and Clinical Psychology, 60, 174-184.
Cole, P. M., \& Woolger, C. (1989). Incest survivors: The relation of their perceptions of their parents and their own parenting attitudes. Child Abuse \& Neglect, 13, 409-416.

Cole, P. M., Woolger, C., Power, T. G., \& Smith, K. D. (1992). Parenting difficulties among incest survivors of father-daughter incest. Child Abuse \& Neglect, 16, 239-249.

Conte, J. R., \& Schuerman, J. R. (1987). Factors associated with an increased impact of child sexual abuse. Child Abuse and Neglect, 11, 201-211.

Courtois, C. A. (1988). Healing the incest wound. New York: W. W. Norton \& Company.

Cross, W. (2001). A personal history of childhood sexual abuse: Parenting patterns and problems. Clinical Child Psychology \& Psychiatry, 6, 563-574.

Daro, D. (1988). Confronting child abuse: Research for effective program design. New York: Free Press.

Davis, J., \& Petretic-Jackson, P. (2000). The impact of child sexual abuse on adult interpersonal functioning: A review and synthesis of the empirical literature. Aggression and Violent Behavior: A Review Journal, 5, 291-328.

Deblinger, E., \& Heflin, A. H. (1996). Treating sexually abused children and their nonoffending parents: A cognitive behavioral approach. Thousand Oaks, CA: Sage.

Deblinger, E., Lippmann, J., \& Steer, R. (1996). Sexually abused children suffering from posttraumatic stress symptoms: Initial treatment outcome findings. Child Maltreatment, 1, 310-321.

Deblinger, E., McLeer, S., \& Henry, D. (1990). Cognitive behavioral treatment for sexually abused children suffering PTSD: Preliminary findings. Journal of the American Academy of Child and Adolescent Psychiatry, 29, 747-752.

Deblinger, E., Stauffer, L., \& Landsberg, C. (1994). The impact of a history of child sexual abuse on maternal response to allegations of sexual abuse concerning her child. Journal of Child Sexual Abuse, 3, 67-75.

Deblinger, E., Steer, R., \& Lippmann, J. (1999). Two-year followup study of cognitive behavioral therapy for sexually abused children suffering post-traumatic stress symptoms. Child Abuse \& Neglect, 23(12), 1371-1378.

De Jong, A. R. (1988). Maternal responses to the sexual abuse of their children. Pediatrics, 81, 14-21.

DiLillo, D. (2001). Interpersonal functioning among women reporting a history of childhood sexual abuse: Empirical findings and methodological issues. Clinical Psychology Review, 21, 553-576.

DiLillo, D., Giuffre, D., Tremblay, G. C., \& Peterson, L. (2001). A closer look at the nature of intimate partner violence reported by women with a history of child sexual abuse. Journal of Interpersonal Violence, 16, 116-132.

DiLillo, D., \& Long, P. J. (1999). Perceptions of couple functioning among female survivors of child sexual abuse. Journal of Child Sexual Abuse, 7, 59-76.

DiLillo, D., Tremblay, G. C., \& Peterson, L. (2000). Linking childhood sexual abuse and abusive parenting: The mediating role of maternal anger. Child Abuse \& Neglect, 24, 767-779.

Donaldson, M. A., \& Gardner, R. (1985). Diagnosis and treatment of traumatic stress among women after childhood incest. In C. R. Figley (Ed.), Trauma and its wake: The study and treatment of post-traumatic stress disorder (pp. 33-347). New York: Bruner/ Mazel.

Douglas, A. R. (2000). Reported anxieties concerning intimate 
parenting in women sexually abused as children. Child Abuse \& Neglect, 24, 425-434.

Dubowitz, H., Black, M. M., Kerr, M. A., Hussey, J. M., Morrel, T. M., Everson, M. D., et al. (2001). Type and timing of mothers' victimization: Effects on mothers and children. Pediatrics, 107, 728-735.

Egeland, B., Breitenbucher, M., \& Rosenberg, D. (1981). Prospective study of the significance of life stress in the etiology of child abuse. Annual Progress in Child Psychiatry \& Child Development, 666-682.

Elliott, A. N., \& Carnes, C. N. (2001). Reactions of nonoffending parents to the sexual abuse of their children: A review of the literature. Child Maltreatment, 6, 314-331.

Faller, K. C. (1989). Why sexual abuse? An exploration of the intergenerational hypothesis. Child Abuse and Neglect, 13, 543-548.

Fergusson, D. M., \& Mullen, P. E. (1999). Childhood sexual abuse: an evidence-based perspective. Thousand Oaks, CA: Sage. Finkelhor, D. (1979). Sexually victimized children. New York: The Free Press.

Finkelhor, D., Hotaling, G. T., Lewis, I. A., \& Smith, C. (1990). Sexual abuse in a national survey of adult men and women: Prevalence, characteristics and risk factors. Child Abuse \& Neglect, 14, 19-28.

Gelles, R. J., \& Straus, M. A. (1987). Is violence toward children increasing? Journal of Interpersonal Violence, 2, 212-222. Goodwin, J., McCarthy, T., \& DiVasto, P. (1981). Prior incest in mothers of sexually abused children. Child Abuse \& Neglect, 5, 87-96.

Green, A. H., Coupe, P., Fernandez, R., \& Stevens, B. (1995). Incest revisited: Delayed post-traumatic stress disorder in mothers following the sexual abuse of their children. Child Abuse \& Neglect, 19, 1275-1282.

Grocke, M., Smith, M., \& Graham, P. (1995). Sexually abused and nonabused mothers' discussions about sex and their children's sexual knowledge. Child Abuse \& Neglect, 19, 985-996.

Hall, L. A., Sachs, B., \& Rayens, M. K. (1998). Mothers' potential for child abuse: The roles of childhood abuse and social resources. Nursing Research, 47, 87-94.

Hansen, D. J., Warner-Rogers, J. E., \& Hecht, D. B. (1998). Implementing and evaluating an individualized behavioral intervention program for maltreating families: Clinical and research issues. In J. R. Lutzker (Ed.), Handbook of child abuse research and treatment (pp. 133-158). New York: Plenum.

Harter, S., Alexander, P. C., \& Neimeyer, R. A. (1988). Long-term effects of incestuous child abuse in college women: Social adjustment, social cognition, and family characteristics. Journal of Consulting and Clinical Psychology, 56, 5-8.

Heriot, J. (1996). Maternal protectiveness following the disclosure of intrafamilial child sexual abuse. Journal of Interpersonal Violence, 11, 181-194.

Herman, J. L., \& Hirschman, L. (1981). Father-daughter incest. Cambridge, MA: Harvard University Press.

Herman-Giddens, M. E., Kotch, J. B., Browne, D. C., Ruina, E., Winsor, J. R., Jung, J., et al. (1998). Childbearing patterns in a cohort of women sexually abused as children. Journal of Interpersonal Violence, 13, 504-513.

Herman-Giddens, M. E., Sandler, A. D., \& Friedman, N. E. (1988). Sexual precocity in girls: An association with sexual abuse? American Journal of Diseases of Children, 142, 431-433.

Herrenkohl, E. C., Herrenkohl, R. C., \& Toedter, L J. (1983).
Perspectives on the intergenerational transmission of abuse In D. Finkelhor, R. J. Gelles, G. T. Hotaling, \& M. A. Straus (Eds.), The darkside of families: Current family violence research. Beverly Hills, CA: Sage.

Hiebert-Murphy, D. (1998). Emotional distress among mothers whose children have been sexually abused: The role of a history of child sexual abuse, social support, and coping. Child Abuse \& Neglect, 22, 423-435.

Higgins, D. J., \& McCabe, M. P. (2000). Multi-type maltreatment and the long-term adjustment of adults. Child Abuse Review, 9, 6-18.

Hubbard, G. B. (1989). Mothers' perception of incest: Sustained disruption and turmoil. Archives of Psychiatric Nursing, 1, 3440.

Jehu, D. (1988). Beyond sexual abuse: Therapy with women who were childhood victims. New York: John Wiley and Sons.

Johnson, B., \& Kenkel, M. (1991). Stress, coping, and adjustment in female adolescent incest victims. Child Abuse \& Neglect, 15, 293-305.

Jurkovic, G. J. (1997). Lost childhoods: The plight of the parentified child. New York: Brunner/Mazel.

Kreklewetz, C. M., \& Piotrowski, C. C. (1998). Incest survivor mothers: Protecting the next generation. Child Abuse \& Neglect, 22, 1305-1312.

Leifer, M., Kilbane, T., \& Grossman, G. (2001). A three-generational study comparing the families of supportive and unsupportive mothers of sexually abused children. Child Maltreatment, 6, 353-364.

Lyons-Ruth, K., \& Block, D. (1996). The disturbed caregiving system: Relations among childhood trauma, maternal caregiving, and infant affect and attachment. Infant Mental Health Journal, 17, 257-275.

Madonna, P. G., Van Scoyk, S., \& Jones, D. P. H. (1991). Family interactions within incest and nonincest families. American Journal of Psychiatry, 148, 46-49.

Maker, A. H., \& Buttenheim, M. (2000). Parenting difficulties in sexual-abuse survivors: A theoretical framework with dual psychodynamic and cognitive-behavioral strategies for intervention. Psychotherapy, 37, 159-170.

Mannarino, A. P., \& Cohen, J. A. (1996). A follow-up study of factors that mediate the development of psychological symptomatology in sexually abused girls. Child Maltreatment, 1, 246-261.

McCloskey, L. A., \& Bailey, J. A. (2000). The intergenerational transmission of risk for child sexual abuse. Journal of Interpersonal Violence, 15, 1019-1035.

Milner, J. S. (1986). The Child Abuse Potential Inventory (2nd ed.). Webster, NC: Psytec.

Morrison, N. C., \& Clavenna-Valleroy, J. (1998). Perceptions of maternal support as related to self-concept and self-report of depression in sexually abused female adolescents. Journal of Child Sexual Abuse, 7, 23-40.

Mullen, P. E., Martin, J. L., Anderson, J. C., Romans, S. E., \& Herbison, G. P. (1994). The effect of child sexual abuse on social, interpersonal, and sexual function in adult life. British Journal of Psychiatry, 165, 35-47.

Nash, L., \& Morrison, W. L. (1984). Manual for the parenting skills inventory. Seattle, WA: Parenting Press.

Newman, A., \& Peterson, C. (1996). Anger of women incest survivors. Sex Roles, 34, 463-474. 
Oates, R. K., Tebbutt, J., Swanston, H., Lynch, D. L., \& O’Toole, B. I. (1998). Prior childhood sexual abuse in mothers of sexually abused children. Child Abuse \& Neglect, 22, 1113-1118.

Paredes, M., Leifer, M., \& Kilbane, T. (2001). Maternal variables related to sexually abused children's functioning. Child Abuse \& Neglect, 25, 1159-1176.

Petterson, S. M., \& Albers, A. B. (2001). Effects of poverty and maternal depression on early child development. Child Development, 72, 1794-1813.

Pianta, R., Egeland, B., \& Erickson, M. (1989). The antecedents of maltreatment: Results of the Mother-Child Interaction Research Project. In D. Cicchetti \& V. Carlson (Eds.), Child maltreatment: Theory and research on the causes and consequences of child abuse and neglect (pp. 203-235). Cambridge, England: Cambridge University Press.

Polusny, M. M., \& Follette, V. M. (1995). Long-term correlates of childhood sexual abuse: Theory and empirical findings. Applied and Preventive Psychology, 4, 143-166.

Robinson, C. C., Mandelco, B., Olsen, S. F., \& Hart, C. H. (1995). Authoritative, authoritarian, and permissive parenting practices: Development of a new measure. Psychological Reports, 77, 819-830.

Rumstein-McKean, O., \& Hunsley, J. (2001). Interpersonal and family functioning of female survivors of childhood sexual abuse. Clinical Psychology Review, 21, 471-490.

Ruscio, A. M. (2001). Predicting the child-rearing practices of mothers sexually abused in childhood. Child Abuse \& Neglect, 25, 369-387.

Russell, D. E. H. (1983). The incidence and prevalence of intrafamilial and extrafamilial sexual abuse of female children. Child Abuse \& Neglect, 7, 133-145.

Russell, D. E. H. (1986). The secret trauma: Incest in the lives of girls and women. New York: Basic Books.

Scott, R. I., \& Day, H. D. (1996). Association of abuse-related symptoms and style of anger expression for female survivors of childhood incest. Journal of Interpersonal Violence, 11, 206-220.

Sedlar, G., \& Hansen, D. J. (2001). Anger, child behavior, and family distress: Further evaluation of the Parental Anger Inventory. Journal of Family Violence, 16, 361-373.

Seifer, R., \& Dickstein, S. (1993). Parental mental illness and infant development. In C. H. Zeanah (Ed.), Handbookof infant mental health (pp. 120-142). New York: Guilford.

Spieker, S. J., Bensley, L., McMahon, R. J., Fung, H., \& Ossiander, E. (1996). Sexual abuse as a factor in child maltreatment by adolescent mothers of preschool aged children. Development and Psychopathology, 8, 497-509.

Sroufe, L. A., Jacobvitz, D., Mangelsdorf, S., De Angelo, E., \& Ward, M. J. (1985). Generational boundary dissolution between mothers and their preschool children: A relationship systems approach. Child Development, 56, 317-325.

Stauffer, L. B., \& Deblinger, E. (1996). Cognitive behavioral groups for nonoffending mothers and their young sexually abused children: A preliminary treatment outcome study. Child Maltreatment, 1, 65-76.

Straus, M. A., Gelles, R. J., \& Steinmetz, S. K. (1980). Behind closed doors: Violence in the American family. Garden City, NY: Anchor.
Timmons-Mitchell, J., Chandler-Holtz, D., \& Semple, W. E. (1996). Post-traumatic stress symptoms in mothers following children's reports of sexual abuse: An exploratory study. American Journal of Orthopsychiatry, 66, 463-467.

Timmons-Mitchell, J., Chandler-Holtz, D., \& Semple, W. E. (1997). Post-traumatic stress disorder symptoms in child sexual abuse victims and their mothers. Journal of Child Sexual Abuse, 6(4), $1-14$.

Trickett, P. K., \& Putnam, F. W. (1993). Impact of child sexual abuse on females: Toward a developmental, psychobiological integration. Psychological Science, 4, 81-87.

Voth, P. F., \& Tutty, L. M. (1999). Daughter's perceptions of being mothered by an incest survivor: A phenomenological study. Journal of Child Sexual Abuse, 8, 25-43.

Westen, D., Ludolph, P., Misle, B., Ruffins, S., \& Block, J. (1990). Physical and sexual abuse in adolescent girls with borderline personality disorder. American Journal of Orthopsychiatry, 60, 55-66.

Whipple, E. E., \& Webster-Stratton, C. (1991). The role of parental stress in physically abusive families. Child Abuse \& Neglect, $15,279-291$.

Widom, C. S. (2000). Motivation and mechanisms in the "cycle of violence". In D. J. Hansen (Ed.), Motivation and Child Maltreatment. (pp. 1-37). Lincoln: University of Nebraska Press.

Widom, C. S., \& Kuhns, J. B. (1996). Childhood victimization and subsequent risk for promiscuity, prostitution, and teenage pregnancy: A prospective study. American Journal of Public Health, 86, 1607-1612.

Wilson, A. E., Calhoun, K. S., \& Bernat, J. A. (1999). Risk recognition and trauma-related symptoms among sexually revictimized women. Journal of Consulting \& Clinical Psychology, 67, 705-710.

Zierler, S., Feingold, L., Laufer, D., Velentgas, P., KantrowitzGordon, L., \& Mayer, K. (1991). Adult survivors of childhood sexual abuse and subsequent risk of HIV infection. American Journal of Public Health, 81, 572-575.

Zuravin, S. J., \& Fontanella, C. (1999). Parenting behaviors and perceived parenting competence of child sexual abuse survivors. Child Abuse \& Neglect, 23, 623-632.

Zuravin, S., McMillen, C., DePanfilis, D., \& Risley-Curtiss, C. (1996). The intergenerational cycle of maltreatment: Continuity versus discontinuity. Journal of Interpersonal Violence, 11, 315-334.

David DiLillo, Ph.D., is an assistant professor of clinical psychology at the University of Nebraska-Lincoln. His primary research and clinical interests lie in the area of family violence, particularly issues related to the long-term adjustment of those who have experienced various forms of childhood trauma and maltreatment. Dr. DiLillo maintains a secondary research interest in the etiology, prevention, and psychological consequences of unintentional injury.

Amy Damashekis a doctoral candidate in child clinical psychology at the University of Missouri-Columbia. Her research interests include child maltreatment prevention, parent training, family therapy, and child unintentional injury prevention. Her clinical interests also involve parent training and family therapy. 